Araştırma Makalesi (Research Article)

Hasan DEMIRKAN1

Süleyman TÜRKSEVEN1

YıldIz NEMLi 1

Ahmet ULUDAĞ²

Koray KAÇAN ${ }^{3}$

${ }^{1}$ Ege Üniversitesi, Ziraat Fakültesi, Bitki Koruma Bölümü, 35100 İmir/Türkiye

e-posta: hasan.demirkan@hotmail.com

2 Onsekiz Mart Üniversitesi, Ziraat Fakültesi, Bitki Koruma Bölümü, 35100 Çanakkale/Türkiye

${ }^{3}$ Bornova Zirai Mücadele Araştırma İstasyonu, İzmir/Türkiye

Anahtar Sözcükler:

Domates, canavar otu, Phelipanche, herbisit, kimyasal mücadele

Key Words:

Tomato, broomrape, Phelipanche, herbicide, chemical control

\section{Domateste Canavar Otuna (Phelipanche ramosa (L.) Pomel/ P.aegyptiaca (Pers.) Pomel) Karşı Bazı Kimyasal Kontrol Metodlarının Araştırılması ${ }^{4}$}

\author{
Investigation on Chemical Control of Broomrape \\ (Phelipanche ramosa (L.) Pomel/ P.aegyptiaca (Pers.) Pomel) \\ in Tomato Fields
${ }^{4}$ Tamamlanmış olan TUBITAK 105G080 no'lu Ülkesel Canavar Otu (Orobanchespp.) Projesine bağlı 106G074 no'lu alt projedir.

Alını̧̧ (Received):05.11.2013

Kabul tarihi (Accepted): 10.11.2013

\section{ÖZET}

Tarla denemeleri Çanakkale'nin Kumkale İlçesi Tevfikiye köyünde 2008 ve 2009 yılları arasında kurulmuştur. Bu çalışmada bazı herbisitlerin farklı dozları (imazapic $5 \mathrm{ml} / \mathrm{da}$, glyphosate $5 \mathrm{ml} / \mathrm{da}$, imazethapyr $20 \mathrm{ml} / \mathrm{da}$, rimsulfuron $5 \mathrm{~g} / \mathrm{da}$, chlorsulfuron $0,24-0,48 \mathrm{ml} / \mathrm{da}$ ) domateste tarla koşullarında çıkış sonrası uygulanmıştır. Sonuç olarak her iki yılda da glyphosate uygulamasının yüksek etkili (\% 84,1 ve $\% 74$ ) olduğu bulunmuştur. İlk yıl imazapic ve iki doz chlorsulfuron uygulaması etkisiz bulunurken, ikinci yıl bu üç uygulama sırasıyla \% $66.7, \% 71.4$ ve $\% 74.4$ etkili bulunmuştur. Domates verimleri imazapic uygulamaları hariç yapılan uygulamalarda her iki yılda da benzer bulunmuştur $(6983-8299 \mathrm{~kg} / \mathrm{da})$. Fitotoksite nedeniyle her iki yılda da imazapic uygulamalarında en düşük verim değerleri (1321-2680 kg/da) elde edilmiştir. Deneme sonuçları domateste canavar otu mücadelesinde bazı herbisitlerin kullanılmasının mümkün olacağını göstermektedir. Ülkemizin önemli kültür bitkilerinden olan domatesin, en önemli sorunu olan canavar otuna karşı herbisitlerin etkinliği çalışmaları mutlaka devam etmelidir.

\section{ABSTRACT}

Eield trials were established in Tevfikiye Village of Kumkale District in Çanakkale betwen 2008 and 2009. In this study, different doses some herbicides (imazapic $5 \mathrm{ml} / \mathrm{da}$, glyphosate $5 \mathrm{ml} / \mathrm{da}$, imazethapyr $20 \mathrm{ml} / \mathrm{da}$, rimsulfuron $5 \mathrm{~g} / \mathrm{da}$, chlorsulfuron $0.24-0.48 \mathrm{ml} / \mathrm{da}$ ) were applied post emergence on tomato in field conditions. Trials set up with seven different variants and four replicated. Acording to the results; It was found that highest effect to broomrape obtain in glyphosate variant (\% 84.1 and \% 74) in two years. Imazapic and two doses chlorsulfuron were'nt effective in first year. This three variants were efective $\% 66.7, \% 71.4$ and $\% 74.4$ respectively in second year. It was found some tomato yield $(6983-8299 \mathrm{~kg} / \mathrm{da})$ in two years expect imazapic. It was found that the lowest tomato yield obtain (1321-2680 kg/da) in imazapic variant because of the phytotoxicity in two years. As a result of the experiments, show us the possibility of using some herbicides on broomrape control in tomato. Further researches should be done about this issue. 


\section{GíRiş}

Domates, dünyada en çok üretilen ve tüketilen tarım ürünlerinin başında gelmektedir. İnsan beslenmesinde çok önemli bir yeri olması ve bununla ilişkili olarak dondurulmuş konserve, salça, turşu gibi çeşitli kullanım alanlarına sahip olması nedeniyle gıda sanayinde önemli bir yere sahiptir.

Türkiye' de yıllara göre değişmekle birlikte yaklaşık 11.3 milyon ton domates üretilmekte (Anonymous, 2012) , bunun $\% 25$ i işlenmekte, kalanı ise taze olarak değerlendirilmektedir. Gerek gıda maddesi olarak işlenen gerekse taze olarak değerlendirilenin önemli bir kısmı da ihraç edilmesi sebebiyle de ülke ekonomisi açısından önem arz etmektedir.

Türkiye üretim miktarı bakımından Çin ve A.B.D'den sonra 3. sırada yer almaktadır. Ülkemizdeki domates üretimi dünyadaki üretim miktarları açısından da son derece önemli yer tutmaktadır.

Domates yetiştiriciliğinde hastalık ve zararlıların yanı sıra yabancı otlar da ürünü olumsuz yönde etkilemektedir. Yabancı otların türüne, yoğunluğuna ve biyolojisine bağlı olarak verim kayıpları olmaktadır. Sorun olan bu yabancı otlardan canavar otu; obligat kök paraziti olduğundan konukçusuna tamamen bağımlı olması nedeniyle bulunduğu bitkiye önemli zarar vermektedir.

Canavar otlarının binlerce tohum üretmesi, tohumlarının uzun yıllar canlılığını yitirmeden toprakta kalabilmesi ve bu tohumların çok küçük olması nedeniyle çevreye çok kolayca yayılabilmesi, bu yabancı otla mücadeleyi zorlaştıran önemli özelliklerindendir. Bunların yanısıra tam parazit bir yabancı ot olup konukçusu ile çok sıkı ilişkisinden dolayı da bir çok kültür bitkisinde ne yazık ki bu yabancı ota karşı ekonomik ve etkili bir kontrol yöntemi geliştirilememiştir. Canavar otlarına karşı kontrol yöntemlerinin yetersiz kalması da bu yabancı otlarının tarımsal alanlarda her geçen gün öneminin artmasına neden olmaktadır.

Araştırıcılar Phelipanche ramosa L. ve $P$. aegyptiaca Pers.'in ayrımını yapmanın çok güç olduğunu ve bu sebeple bir çok ülkede bu iki türün bir karışım (kompleks) olarak ifade edildiğini ve bu kompleksin özellikle Solanaceae, Brassicaceae, Cucurbitaceae ve Fabaceae familyalarına ait bitkileri parazitlediğini ancak en önemli olarak domateste sorun oluşturduğunu kaydetmişlerdir (Parker 1994, Musselman, 1994).

Canavar otunun çeşitli kültür bitkilerinde meydana getirdiği kayıp oranlarının \% 5- 100 arasında değiştiği yapılan farklı çalışmalarla ortaya konulmuştur (Hodosy,
1981, Sauerborn and Saxena, 1986, Kroshi et al., 1996, Hassanein and Salim, 1999, Goldwasser et al., 2003, Schneeweiss, 2007)

Canavar otunun, Marmara Bölgesi domates dikim alanlarında yıllardan beri önemli bir sorun olduğu bilinmektedir. Öyle ki; canavar otu ile bulaşık üretim alanlarında domates üretiminden vazgeçmek durumunda olan bölgeler bile mevcuttur.

Canavar otları ile mücadelede kültürel yöntem (elle çekme, geç ekim, tuzak bitki, derin sürüm) dayanıklı çeşit, kimyasal kontrol (herbisitler, toprak fumigantları), fiziksel kontrol (solarizasyon), biyolojik kontrol (böcek ve funguslar) gibi yöntemler bulunmasına rağmen bunlardan hiçbiri tek başına yeterli, uygulanması kolay ve ekonomik olmamıştır. Bu nedenle bu yabancı otla mücadelede en etkili metodun adı geçen yöntemlerin entegre edilmesi ile sağlandığı bildirilmektedir.

Ülkemizde tütün, ayçiçeği ve mercimekte canavarotuna karşı ruhsat almış olan imazapic etkili maddeli herbisit 2014'ün sonlarına doğru tamamen kullanımdan kalkacağı bildirilmektedir. Bu nedenle yurt dışında bu alanda yapılan çalışmalar değerlendirilerek bazı herbisitlerin denemeye alınması ve elde edilecek sonuçların olumlu bulunması halinde ülkemizde çok büyük alanlarda önemli verim kayıplarına neden olan canavar otuna karşı bir adım atılması planlanmıştır.

\section{MATERYAL VE YÖNTEM}

\section{Materyal}

Bu çalışma Çanakkale İli Kumkale Beldesi Tevfikiye Köyünde doğal olarak Phelipanche ramosal P.aegyptiaca ile bulaşık tarlalarda yürütülmüştür. Deneme iki yıl (2008-2009) sürmüş olup, iki yılda da Sun 6200 (Nunhems) domates çeşidi tarlaya dikilmiştir. Denemelerde kullanılan herbisitler ve dozları Çizelge 1 'de verilmiştir.

Çizelge 1. Denemede kullanılan herbisitler ve dozları Table 1. Herbicides and doses in experiments

\begin{tabular}{|c|c|c|}
\hline Karakter & Doz & $\begin{array}{c}\text { Uygulama zamanı ve } \\
\text { sayısı }\end{array}$ \\
\hline Rimsulfuron & $5 \mathrm{~g} / \mathrm{da}$ & \multirow{6}{*}{$\begin{array}{c}15 \text { gün ara ile } 2 \\
\text { uygulama }\end{array}$} \\
\hline İmazethapyr & $20 \mathrm{ml} / \mathrm{da}$ & \\
\hline Glyphosate & $5 \mathrm{ml} / \mathrm{da}$ & \\
\hline İmazapic & $5 \mathrm{ml} / \mathrm{da}$ & \\
\hline Chlorsulfuron & $0.24 \mathrm{ml} / \mathrm{da}$ & \\
\hline Chlorsulfuron & $0.48 \mathrm{ml} / \mathrm{da}$ & \\
\hline Kontrol & - & - \\
\hline
\end{tabular}




\section{Yöntem}

Altı farklı herbisit uygulamasının domateste canavar otu çıkışına etkisini incelemek amacı ile 2008 ve 2009 yıllarında iki tarla denemesi kurulmuştur. Denemeler tesadüf blokları deneme desenine göre dört tekerrürlü kurulmuştur.

Kontrol dahil 7 karakterli olarak (imazapic (5 $\mathrm{ml} / \mathrm{da})$, glyphosate $(5 \mathrm{ml} / \mathrm{da})$, imazethapyr $(20 \mathrm{ml} / \mathrm{da})$, rimsulfuron $(5 \mathrm{~g} / \mathrm{da})$, chlorsulfuron $(0.24 \mathrm{ml} / \mathrm{da}$ ve 0.48 $\mathrm{ml} / \mathrm{da}$ ) yürütülen denemelerde toplam 28 parsel oluşturulmuştur. Her parselin boyutu $20 \mathrm{~m}^{2}(4 \mathrm{~m} \times 5 \mathrm{~m})$ olup karakterler arası $1 \mathrm{~m}$, tekerrürler arası $2 \mathrm{~m}$ emniyet şeridi bırakılmıştır. Her bir parsele 5 metre uzunluğunda 4 domates sırası denk gelmiştir. Gübreleme sulama ve bakım işlemleri çiftçi koşullarında olmuştur. Deneme kurulumu ve tüm uygulamaların yapıldığı tarihler Çizelge 2'de yer almaktadır.

Çizelge 2. Deneme kurma ve uygulama takvimi Table 2. Schedule of treatments

\begin{tabular}{|l|c|c|}
\hline Yapılan İşlem & $\mathbf{2 0 0 8}$ & $\mathbf{2 0 0 9}$ \\
\hline Domates dikimi & 10.06 .2008 & 03.05 .2009 \\
\hline $\begin{array}{l}\text { Herbisitlerin ilk uygulandığı } \\
\text { tarih }\end{array}$ & 10.07 .2008 & 03.06 .2009 \\
\hline $\begin{array}{l}\text { Herbisitlerin ikinci uygulandığı } \\
\text { tarih }\end{array}$ & 24.07 .2008 & 16.06 .2009 \\
\hline İlk sayımların yapıldığı tarih & 05.08 .2008 & 23.07 .2009 \\
\hline İkinci sayımların yapıldığı tarih & 21.08 .2008 & 06.08 .2009 \\
\hline Hasat tarihleri & 04.09 .2008 & 23.07 .2009 \\
& 20.09 .2008 & 06.08 .2009 \\
\hline
\end{tabular}

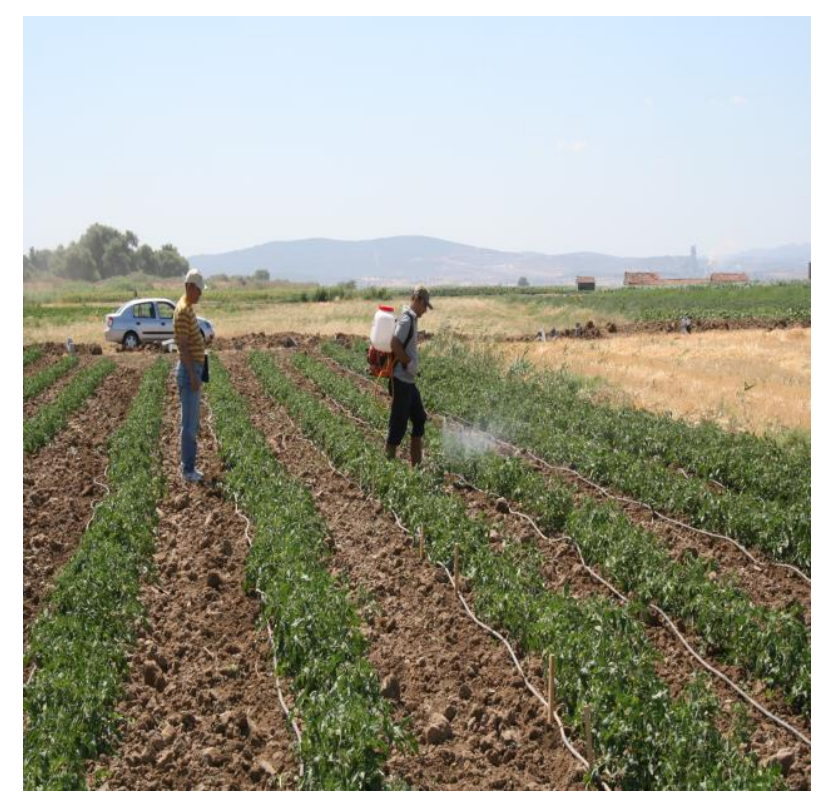

Şekil 1. Deneme alanında ilaçlama anından bir görüntü Figure 1. Herbicide application
Uygulamaların canavar otuna etkileri, çıkan canavar otu dal sayısı ve bunların yaş ile kuru ağırlıkları esas alınarak yapılmıştır.

Deneme alanında 05.08.2008 - 21.08.2008 ve 23.07.2009 - 06.08.2009 tarihlerinde canavar otu çıkışı sayımları yapılmış ve çıkan bitkilerin yaş ve kuru ağırlıklarını değerlendirmek üzere toprak yüzeyinden kesilerek ayrı ayrı kese kağıtlarına alınmıştır. Deneme alanında $5 \mathrm{~m}$ eninde $4 \mathrm{~m}$ uzunluğundaki her parselde 4 sıraya ilaçlama yapılmış ancak ortadaki 2 sırada sayımlar ve hasatlar gerçekleştirilmiştir.

Her parselden ayrı ayrı alınan etiketli canavar otu bitkileri laboratuarda sayılmış ve daha sonra bu örneklerin yaş ağırlıkları alınmıştır.

Yaş ağırlıkları tartılmış canavarotları, kuru ağırlıkları alınmak üzere ayrı ayrı poşetlere konmuş ve kurutulmak üzere $100^{\circ} \mathrm{C}$ etüvde 24 saat süre ile bırakılmıştır.

Karakterler arasındaki farkların önemini belirlemek amacı ile SPSS 11.0 paket istatistik programında Duncan çoklu karşılaştırma testi uygulanarak istatistiki analizler yapışmıştır. Elde edilen değerlere Abbott formülü uygulanarak yüzde etki değerleri hesaplanmıştır.

\section{BULGULAR \\ Farklı Herbisit Uygulamalarının Canavar Otu Dal Sayısına Etkileri}

Altı farklı herbisit uygulamasının, toprak üstüne çıkan canavar otu dal sayısına etkileri tarla denemelerinde saptanmıştır. Elde edilen sonuçlar Çizelge 3'de görülmektedir.

Çizelge 3. Herbisitlerin canavarotu dal sayılarına etkileri (dal sayısi $/ 10 \mathrm{~m}^{2}$ )

Table 3. The effect of herbicides on broomrape emergence (broomrape shoot $/ 10 \mathrm{~m}^{2}$ )

\begin{tabular}{|l|l|l|l|l|}
\hline \multirow{2}{*}{ Karakter } & \multicolumn{2}{|c|}{2008} & \multicolumn{2}{c|}{2009} \\
\cline { 2 - 5 } & $\begin{array}{l}\text { Ort. } \\
\text { (adet)* }\end{array}$ & $\begin{array}{l}\text { Etki } \\
\text { (\%)** }\end{array}$ & $\begin{array}{l}\text { Ort. } \\
\text { (adet)* }\end{array}$ & $\begin{array}{l}\text { Etki } \\
\text { (\%)** }\end{array}$ \\
\hline Kontrol & $275.3 \mathrm{AB}$ & --- & $341.0 \mathrm{~B}$ & --- \\
\hline $\begin{array}{l}\text { Imazethapyr } \\
\text { (20 ml/da) }\end{array}$ & $99.1 \mathrm{~B}$ & 64.0 & $56.0 \mathrm{~A}$ & 83.5 \\
\hline $\begin{array}{l}\text { Rimsulfuron } \\
\text { (5 g/da) }\end{array}$ & $475.6 \mathrm{~A}$ & - & $253.7 \mathrm{~B}$ & 25.4 \\
\hline $\begin{array}{l}\text { Imazapic } \\
\text { (5 ml/da) }\end{array}$ & $229.1 \mathrm{AB}$ & 16.8 & $113.5 \mathrm{~A}$ & 66.7 \\
\hline $\begin{array}{l}\text { Chlorsulfuron } \\
\text { (0.24 ml/da) }\end{array}$ & $253.5 \mathrm{AB}$ & 7.9 & $154.1 \mathrm{~A}$ & 54.8 \\
\hline $\begin{array}{l}\text { Chlorsulfuron } \\
\text { (0.48 ml/da) }\end{array}$ & $153.5 \mathrm{~B}$ & 44.3 & $97.2 \mathrm{~A}$ & 71.4 \\
\hline $\begin{array}{l}\text { Glyphosate } \\
\text { (5 ml/da) }\end{array}$ & $43.7 \mathrm{~B}$ & 84.1 & $87.2 \mathrm{~A}$ & 74.4 \\
\hline
\end{tabular}

*SPSS paket programında Duncan testi $(p<0,05)$

**Abbott formülüne göre $\%$ etki. 
Çizelge 3 incelendiğinde, 2008 sonuçlarında en yüksek etkiyi glyphosate (\% 84.1 etki) gösterirken, onu $\% 64.0$ etki ile imazethapyr izlemiştir. Imazapic ve chlorsulfuron $(0.24 \mathrm{ml} / \mathrm{da})^{\prime}$ da düşük etki görülmüşken, rimsulfuron etkisiz bulunmuştur. İstatistiksel olarak bakıldığında ise, imazethapyr, chlorsulfuron $(0.48$ $\mathrm{ml} / \mathrm{da}$ ) ve glyphosate bir grup oluşturmuşlardır. 2009 sonuçlarına göre, imazethapyr en yüksek etkiyi (\% 83.5) gösterirken bunu glyphosate $\% 74.41$ ve chlorsulfuron'un $0.48 \mathrm{ml} / \mathrm{da}$ 'lık dozu (\% 71.48) izlemiştir. Rimsulfuron ise etkisiz (\% 25.4) bulunmuştur. Rimsulfuron ayrı bir grupta (B) yer alırken, diğer tüm uygulamalar aynı grupta (A) yer almışlardır.

Yurt içinde ve yurt dışında yapılan bazı çalışmalarda da canavar otuna karşı glyphosate'in (Kıtıkı ve ark., 1993, Parker, 1994), metam sodyum'un (Goldwasser et al., 1995), imazapic'in (Özge ve ark., 1997), chlorsulfuron'un (Quasem, 1998, Hershenhorn et al., 1998), rimsulfuron'un (Goldwasser et al., 2001; Haidar et al., 2005) etkili olduğuna dair sonuçlar görülmektedir,
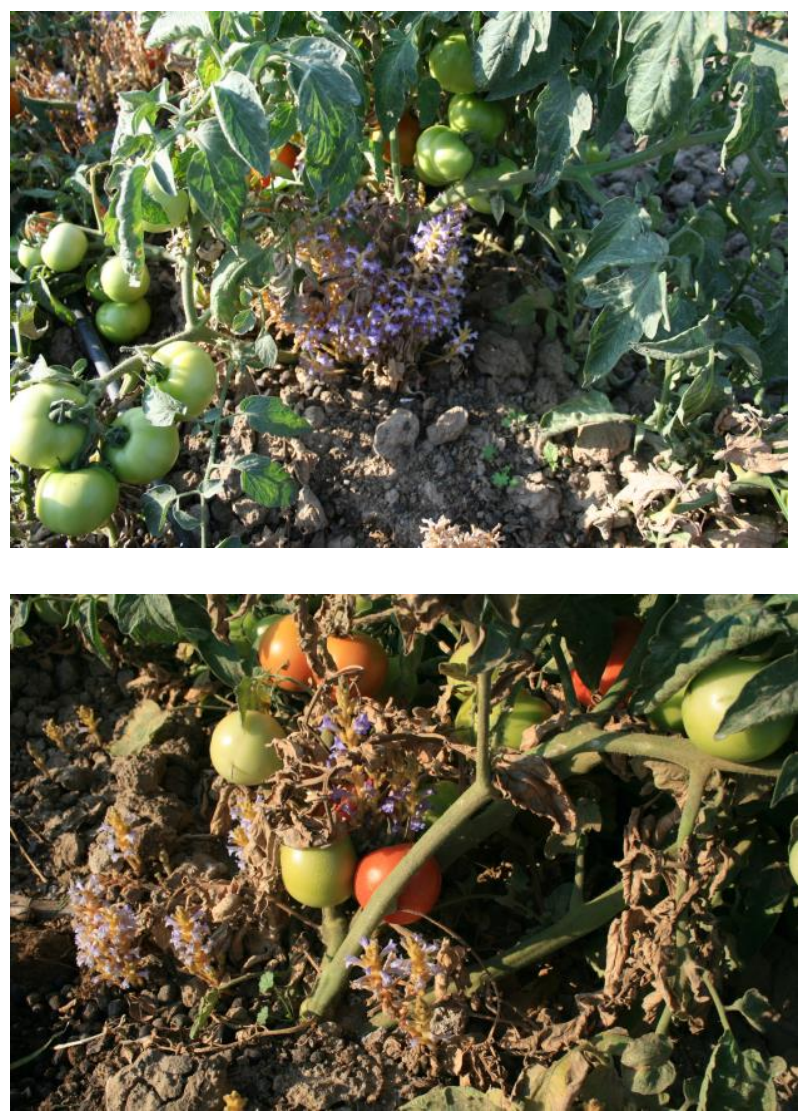

Şekil 2. Domateste Phelipanche ramosa/aegyptiaca Figure 2. Phelipanche ramosa/aegyptiaca in tomato

\section{Herbisitlerin Canavar Otu Yaş ve Kuru Ağırlığına Etkileri}

Çizelge 4. Farklı herbisit uygulamalarının canavar otu yaş ağırlığına etkileri

Table 4. The effect of herbicide on wet weight of broomrape

\begin{tabular}{|l|l|l|l|l|}
\hline \multirow{2}{*}{ Karakter } & \multicolumn{2}{|c|}{$\mathbf{2 0 0 8}$} & \multicolumn{2}{c|}{2009} \\
\cline { 2 - 5 } & $\begin{array}{c}\text { Ort. } \\
\left(\mathbf{g} / \mathbf{1 0} \mathbf{~ m}^{\mathbf{2}}\right)^{*}\end{array}$ & $\begin{array}{c}\text { Etki } \\
(\%)^{* *}\end{array}$ & $\begin{array}{c}\text { Ort. } \\
\left(\mathbf{g} / \mathbf{1 0} \mathbf{~ m}^{2}\right)^{*}\end{array}$ & $\begin{array}{c}\text { Etki } \\
(\%)^{* * *}\end{array}$ \\
\hline Kontrol & $298.8 \mathrm{AB}$ & - & $385.9 \mathrm{C}$ & --- \\
\hline $\begin{array}{l}\text { Imazethapyr } \\
\text { (20 cml/da) }\end{array}$ & $101.5 \mathrm{~A}$ & 66.0 & $62.8 \mathrm{~A}$ & 83.7 \\
\hline $\begin{array}{l}\text { Rimsulfuron } \\
\text { (5 g/da) }\end{array}$ & $439.7 \mathrm{~B}$ & - & $260.3 \mathrm{~B}$ & 32.5 \\
\hline $\begin{array}{l}\text { Imazapic } \\
\text { (5 ml/da) }\end{array}$ & $273.8 \mathrm{AB}$ & 8.3 & $119.5 \mathrm{~A}$ & 69.0 \\
\hline $\begin{array}{l}\text { Chlorsulfuron } \\
\text { (0.24 ml/da) }\end{array}$ & $232.5 \mathrm{~B}$ & 22.1 & $166.5 \mathrm{AB}$ & 56.8 \\
\hline $\begin{array}{l}\text { Chlorsulfuron } \\
\text { (0.48 ml/da) }\end{array}$ & $154.8 \mathrm{~B}$ & 48.1 & $100.8 \mathrm{~A}$ & 80.9 \\
\hline $\begin{array}{l}\text { Glyphosate } \\
\text { (5 ml/da) }\end{array}$ & $65.2 \mathrm{~A}$ & 78.1 & $113.2 \mathrm{~A}$ & 75.0 \\
\hline
\end{tabular}

*SPSS paket programında Duncan testi $(p<0,05)$

${ }^{* *}$ Abbott formülüne göre \% etki

Çizelge 4 incelendiğinde, 2008 sonuçlarında altı uygulama arasında glyphosate uygulaması canavar otu yaş ağırlığına en yüksek etkili (\% 78.1) bulunmuştur. Bunu imazethapyr uygulaması \% 66 etkiyle izlemiştir. Bu iki uygulama istatistiki olarak aynı grupta (A) yer almıştır. Diğer karakterlerde etki \% 8.3 ile \% 48.1 arasında değişim göstermiştir. 2009 sonuçlarına göre ise, en yüksek etki sırasıyla imazethapyr (\% 83.7), chlorsulfuron $(0.48 \mathrm{ml} / \mathrm{da}$ ) (\% 80.9) ve glyphosate (\% 75.0)'den elde edilmiştir. Üç uygulama da aynı grupta (A) yer almıştır.

Farklı herbisit uygulamalarının canavar otunun kuru ağırlığına etkileri Çizelge $5^{\prime}$ de görülmektedir. Elde edilen sonuçlar (2008 yılı verilerine göre), yaş ağırlığa etkilerine paralel bulunurken glyphosate uygulaması canavar otu kuru ağırlığına en yüksek etkili (\% 87.5) bulunmuştur. Bunu imazethapyr uygulaması \% 73.8 etkiyle izlemiştir. Bu iki uygulama istatistiki olarak aynı grupta (A) yer almıştır. Diğer karakterlerde etki \% 18.8 ile \% 60.4 arasında değişim göstermiştir.

2009 yılı sonuçlarına göre, Imazethapyr (\% 89.9), chlorsulfuron ( $0.48 \mathrm{ml} / \mathrm{da}$ ) ve glyphosate aynı etkiyi (\% 84.1) göstermişler ve istatistiki olarak aynı grupta (A) yer almışlardır. Imazapic ve chlorsulfuron $(0.24 \mathrm{ml} / \mathrm{da})$ farklı bir grubu (AB) oluşturmuşlardır. Diğer uygulamalarda etki \% 42.8 - 75.1 arasında değişim göstermiştir (Çizelge 5). 
Çizelge 5. Farklı herbisit uygulamalarının canavar otu kuru ağırlığına etkileri

Table 5. The effect of herbicide on dry weight of broomrape

\begin{tabular}{|l|l|l|l|l|}
\hline \multirow{2}{*}{ Karakter } & \multicolumn{2}{|c|}{2008} & \multicolumn{2}{c|}{2009} \\
\cline { 2 - 5 } & $\begin{array}{l}\text { Ort. } \\
(\mathbf{g} / 10 \\
\left.\mathbf{m}^{2}\right)^{*}\end{array}$ & $\begin{array}{l}\text { Etki } \\
(\%)^{* *}\end{array}$ & $\begin{array}{l}\text { Ort. } \\
\text { (g/10 } \\
\left.\mathbf{m}^{2}\right)^{*}\end{array}$ & $\begin{array}{l}\text { Etki } \\
(\%)^{* *}\end{array}$ \\
\hline Kontrol & $82.1 \mathrm{AB}$ & - & $117.7 \mathrm{C}$ & - \\
\hline $\begin{array}{l}\text { Imazethapyr } \\
(20 \mathrm{ml} / \text { da) }\end{array}$ & $21.5 \mathrm{~A}$ & 73.8 & $11.8 \mathrm{~A}$ & 89.9 \\
\hline $\begin{array}{l}\text { Rimsulfuron } \\
\text { (5 g/da) }\end{array}$ & $118.1 \mathrm{~B}$ & - & $67.3 \mathrm{~B}$ & 42.8 \\
\hline $\begin{array}{l}\text { Imazapic } \\
\text { (5 ml/da) }\end{array}$ & $66.6 \mathrm{AB}$ & 18.8 & 29.3 & 75.1 \\
\hline $\begin{array}{l}\text { Chlorsulfuron } \\
\text { (0.24 ml/da) }\end{array}$ & $66.6 \mathrm{AB}$ & 18.8 & $\begin{array}{c}43.1 \\
\mathrm{AB}\end{array}$ & 63.3 \\
\hline $\begin{array}{l}\text { Chlorsulfuron } \\
\text { (0.48 ml/da) }\end{array}$ & $32.5 \mathrm{AB}$ & 60.4 & $18.6 \mathrm{~A}$ & 84.1 \\
\hline $\begin{array}{l}\text { Glyphosate } \\
\text { (5 ml/da) }\end{array}$ & $10.2 \mathrm{~A}$ & 87.5 & $18.7 \mathrm{~A}$ & 84.1 \\
\hline
\end{tabular}

*SPSS paket programında Duncan testi $(p<0,05)$

${ }^{* *}$ Abbott formülüne göre \% etki

Farklı Uygulamaların Domates Verimine Etkileri

Uygulamaların domates verimine etkileri ve diğer bir değişle karakterlerin verime etkileri ve karşılaştırılması yapılmıştır (Çizelge 6).

Çizelge 6. Domates hasat sonuçları $(\mathrm{kg} / \mathrm{da})$

Table 6. Harvest results of potato ( $\mathrm{kg} / \mathrm{da}$ )

\begin{tabular}{|l|l|l|l|l|}
\hline \multirow{2}{*}{ Karakterler } & \multicolumn{2}{|c|}{2008} & \multicolumn{2}{c|}{2009} \\
\cline { 2 - 5 } & $\begin{array}{l}\text { ORT. } \\
\text { (kg/10 } \\
\left.\mathbf{m}^{2}\right)^{*}\end{array}$ & $\begin{array}{l}\text { Verim } \\
\text { kg/da }\end{array}$ & $\begin{array}{l}\text { ORT. } \\
\text { (kg/10 } \\
\left.\mathbf{~ m}^{2}\right)^{*}\end{array}$ & $\begin{array}{l}\text { Verim } \\
\text { kg/da }\end{array}$ \\
\hline Kontrol & 61.7 & $6183.0 \mathrm{~B}$ & 69.7 & $6983.2 \mathrm{~B}$ \\
\hline $\begin{array}{l}\text { İmazethapyr } \\
\text { (20 ml/da) }\end{array}$ & 21.3 & $2144.0 \mathrm{~A}$ & 13.1 & $1321.8 \mathrm{~A}$ \\
\hline $\begin{array}{l}\text { Rimsulfuron } \\
\text { (5 g/da) }\end{array}$ & 59.5 & $5953.0 \mathrm{~B}$ & 82.8 & $8299.1 \mathrm{~B}$ \\
\hline $\begin{array}{l}\text { Imazapic } \\
\text { (5 ml/da) }\end{array}$ & 58.3 & $5845.0 \mathrm{~B}$ & 71.1 & $7118.8 \mathrm{~B}$ \\
\hline $\begin{array}{l}\text { Chlorsulfuron } \\
\text { (0.24 ml/da) }\end{array}$ & 64.1 & $6414.0 \mathrm{~B}$ & 76.2 & $7635.1 \mathrm{~B}$ \\
\hline $\begin{array}{l}\text { Chlorsulfuron } \\
\text { (0.48 ml/da) }\end{array}$ & 62.3 & $6248.0 \mathrm{~B}$ & 73.7 & $7376.3 \mathrm{~B}$ \\
\hline $\begin{array}{l}\text { Glyphosate } \\
\text { (5 ml/da) }\end{array}$ & 57.1 & $5718.0 \mathrm{~B}$ & 81.1 & $8117.2 \mathrm{~B}$ \\
\hline
\end{tabular}

*SPSS paket programında Duncan testi uygulanmıştır.

Çizelge $\sigma^{\prime}$ da görüleceği gibi imazethapyr dışındaki uygulamalar istatistiki olarak aynı grupta (B) yer almışlardır. Verim değerleri de birbirine yakın çıkmıştır. Imazethapyr uygulamasında ise en düşük verim değeri $(2680 \mathrm{~kg} / \mathrm{da})$ alınmıştır. Bu uygulamada fitotoksite görülmüştür. Birinci hasat yapılırken bu uygulamanın yapıldığı parsellerde henüz domatesler olgunlaşmamıştır (2008 yılı hasat sonuçları). Bir sonraki yılda kurulan denemede ise; en yüksek verim $8299.1 \mathrm{~kg} / \mathrm{da}$ ile rimsulfuron uygulamasından alınmıştır. Diğer uygulamalarda ise verim değerleri 6983.2 ile $8117.2 \mathrm{~kg} / \mathrm{da}$ arasındadır. Imazethapyr uygulaması dışındakiler aynı grupta (B) yer almışlardır. İkinci yıl uygulamasında da imazethapyr uygulamasında fitotoksite görülmüştür. Bundan dolayı da verim düşük (1321.8 kg/da) çıkmıştır.

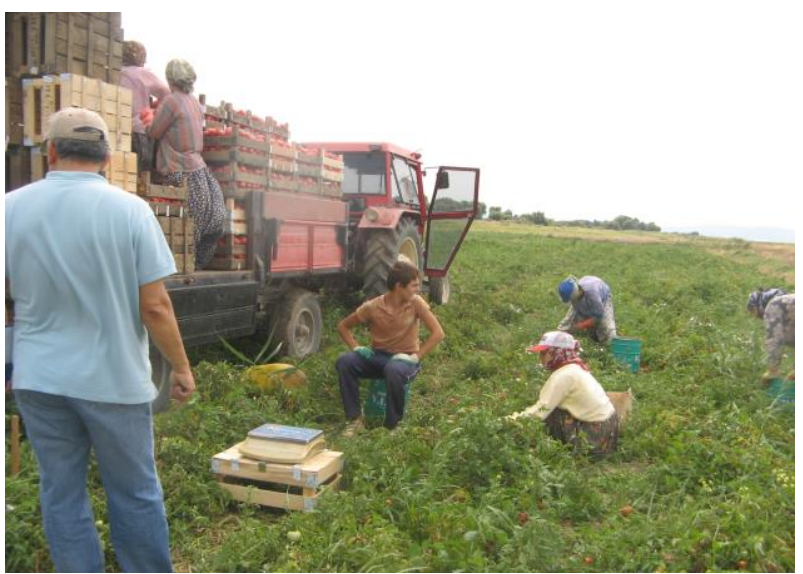

Şekil 3. Domates hasadından bir görünüm Figure 3. Tomato harvest

\section{SONUÇ VE TARTIŞMA}

O.ramosa ve O.aegyptiaca Solanaceae familyasında yer alan birçok kültür bitkisini parazitlemektedir (Parker, 1986). Ülkemizde Solanaceae familyasından domates, patlıcan, patates ve tütünü parazitlediği saptanmıştır (Aksoy ve ark,2009).

Oramosa ve O.aegyptiaca, Orobanche genusu içinde yer almıştır. Ancak yeni kaynaklarda bu iki türün farklı bir genus olan Phelipanche içinde yer alması gerektiğini gerekçeleriyle açıklanmaktadır (Joel, 2009).

Bu çalışma Marmara Bölgesi canavar otu ile bulaşık domates tarlalarında yürütülmüştür. Marmara Bölgesinde sofralık ve sanayi domates üretiminde canavar otu yıllardan beri önemli bir sorun oluşturmaktadır. Canavar otu ile bulaşık alanlarda verim 800 $\mathrm{kg} / \mathrm{da}$ kadar düşerken, bulaşık olmayan alanlarda 5-6 ton/da ürün alınmaktadır.

Canavar otunun ülkemizde ve dünyada tarım alanlarında önemli bir sorun olmasının nedeni kesin ve kalıcı mücadele yöntemlerinin bulunmayışıdır. Kimyasal savaşıma bakıldığında etkinin düşük olduğu görülmektedir (Nemli ve ark. 2009). Mekanik savaş ise iş gücü gerektirmekte ve ekonomik olmamaktadır. 
Bu projede iki yıl (2008 ve 2009 yıllarında) aynı lokasyonda ve aynı karakterlerle denemeler tekrarlanmıştır. Karakterlerin (herbisitlerin) canavar otuna etkilerinde esas olarak canavar otu dal sayısı ve bunların kuru ağırlığı alınmıştır. Yaş ağırlık ikinci derecede önem taşıdığından tartışma kısmında değerlendirmeye alınmamıştır.

Canavar otu dal sayısı esas alındığında (2008 yılı deneme sonuçlarına göre) glyphosate en etkili (\% 84.1) bulunmuş, bunu imazethapyr (\% 64.0) izlemiştir. Diğer uygulamalar yeterli etkiyi gösterememiştir. Ancak 2009 yılı sonuçlarına bakıldığında imazethapyr'in \% 83.5 etki ile birinci sırayı aldığı görülmektedir. Yine 2009 sonuçlarında glyphosate'in (\% 74.4) ve chlorsulfuron'un $(0.48 \mathrm{ml} / \mathrm{da})$ etki bakımın-dan birbirine yakın (\% 71.4) olduğu görülmektedir.

Farklı uygulamaların canavarotu kuru ağırlığına etkilerine bakıldığında (2008 yılı denemelerinde), canavarotu dal sayısı ile büyük ölçüde paralellik göstermiş̧tir. Kuru ağırlık esas alındığında glyphosate en etkili ( $\%$ 87.5) bulunmuş, rimsulfuron ise kontrolden fazla olmasıyla en son sırada yer almıştır. Ancak 2009 yılı denemelerinde ise, imazethapyr (\% 89.9), chlorsulfuron $(0.48 \mathrm{ml} / \mathrm{da})$ ve glyphosate uygulamaları (\% 84.1) etki bakımından ilk sıralarda yer almaktadır.

\section{KAYNAKLAR}

Aksoy,E. A.Aksoy, G.Armağan, M.Arslan, S.Başaran, O.Bayraktar, O.Boz, O.Bozdoğan, F.Bülbül, B.Bükün, L.Büyükkarakuş, A.Demir, H.Demirkan, N.Doğan, F.Erbaş, S.Eymirli, D.Işı1k, K.Kaçan, İ.Kadıŏlu, S.Karaoğlu, E.Kaya, O.Kolören, K.Melan, H.Mennan, Y.Nemli, D.Ögüt, C.Özaslan, S.Öztemiz, F.Pala, M.Ruşen, N.Temel, O.Tetik, N.Tursun, S.Türkseven, A.Uludağ, S.Uygur, F.N.Uygur, T.Üstüner, İ.Üremiş, A.Yazlık, S.Yücel,2010. National Broomrape Project In Turkey. $10^{\text {th }}$ World Congress On Parasitic Plants. 8-12 June 2009, Kuşadas1TURKEY, Proceedings, p: 82-83.

Anonymous, 2012. Türkiye İstatistik Kurumu (TUIK). Bitkisel Üretim İstatistikleri. Haber Bülteni. Sayı : 10780

Goldwasser, Y., Kleifeld, Y., Golan, S., Bargutti, A., Rubin, B., 1995. Dissipation of Metham-sodium from Soil and its Effect on the Control of Orobanche aegyptiaca. Weed Research, 35: 445-452.

Goldwasser, Y., Eizenberg, H., Hershenhorn, J., Plakhine, D., Blumenfeld, T., Buxbaum, H., Golan, S., Kleifeld, Y., 2001. Control of Orobanche aegyptiaca and O. ramosa in Potato. Crop Protection, 20: 403-410.

Goldwasser, Y., Eizenberg, H., Golan, S., Kleifeld, Y., 2003. Control of Orobanche crenata and Orobanche aegyptiaca in Parsley. Crop Protection, 22: 295-305.

Haidar, M.A., Iskandarani, N., Sidahmed, M.M., Darwish, R., 2005. Susceptibility of Orobanche ramosa and potato tolerance to Rimsulfuron. Crop Protection, 24 : 7-13.
Uygulamaların domates verimine etkilerine bakıldığında, 2008 yılında en yüksek verim chlorsulfuron $(0.24 \mathrm{cc} / \mathrm{da})$ uygulamasında $(6414 \mathrm{~kg} / \mathrm{da})$ elde edilmiştir. Diğer uygulamaların verime etkisi birbirine yakın bulunmuştur. Oysa imazethapyr'de $2144 \mathrm{~kg} / \mathrm{da}$ ile en düşük verim alınmıştır. Bu uygulamada domates bitkilerinde fitotoksite görülmüştür. Benzer durum 2009 yılında da görülmüştür.

Domates verimi açısından denemeleri irdeleyecek olursak, 2008 yılı uygulamalarında chlorsulfuron'un $0.48 \mathrm{ml} / \mathrm{da}$ uygulamasında $6.248 \mathrm{~kg} / \mathrm{da}$ verim elde edilerek 2.sıraya yerleşmiştir. Imazethapyr dışındaki tüm uygulamalar istatistiki yönden aynı grupta yer almışlardır. Diğer uygulamalarda verim (imazethapyr hariç) 5.7 - 6.2 ton/da arasında değişmiş ve aynı grupta yer alırken, 2009 yılı verim değerlendirilmelerine bakıldığında; en yüksek verim rimsulfuron $(8299.1 \mathrm{~kg} / \mathrm{da})^{\prime} \mathrm{dan}$ alınmış, bunu glyphosate uygulaması $(8117.2 \mathrm{~kg} / \mathrm{da})$ izlemiştir. Anlaşılacağı gibi 2008 ve 2009 yılı sonuçlarında bir paralellik görülmektedir. Ancak 2009 verim değerlendirilmesinde tüm uygulamalar aynı istatistik grupta (A) yer almıştır.

Ancak üretici koşullarında ümitvar sonuç alınan glyphosate, rimsulfuron ve chlorsulfuron'un çok geniş alanlarda mutlaka denenmesi, domateste çok büyük sorunlara neden olan canavarotu mücadelesi için kesin sonuçlar verebilecektir.

Hassanein, E., Salim, A., 1999. Country Paper About Orobanche and Its Control in Egypt. Advances in Parasitic Weed Control at On-Farm Level, Vol. 11, Join Action to Control Orobanche in the Wana Region, J.Kroschel, M.Abderabihi. H. Betz (Editors), Deutsche Gesellschaft für Technische Zusammenarbeit (GTZ) GmbH, Eschborn, Germany, p. 27-35.

Hershenhorn, J., Goldwasser Y., Plakhine D., Ali R., Blumenfeld T., Bucsbaum H., Herzlinger G., Golan S., Chilf T., Eizenberg H., Dor E. and Kleifeld Y., 1998. Orobanche aegyptiaca Control in Tomato Fields with Sulfonylurea Herbicides. Weed Research, 38: 343-349.

Hodosy, S., 1981. Biological control of Broomrape, Orobanche ramosa, a Tomato Parasite. I. Occurence and Adaptability of Fusarium species to Control Broomrape in Hungary. Zoldsegtermesztesi Kutato Intezet Bulletinge. 1979-80 publ. 1981, 14: 21-29: 17 ref. Veg-Crops Res. Inst., Kecskemet, Hungary.

Joel,D.M.,2009. The new nomenclature of Orobanche and Phelipanche. Weed Research, 49:1-6.

Kıtıkı, A., Açıköz, N., Cinsoy A.S., 1993. Baklada (Vicia faba L.) Orobanşın (Orobanche crenata Forsk.) Kontrolü ve İlaçlamanın Bazı Verim Komponentlerine Etkisi. Türkiye I. Herboloji Kongresi, 3-5 Şubat 1993, Adana.

Kroshi A.A., El-Borollory, M.M., Hassan, E.A., MR., Aboel-suoud, Z., El-deen, Koraim, A., 1996. Host of Orobanche spp. and Yield Losses in Delta and Upper Egypt. In MT. Moreno, JI., 
Cubero, D., Berner, D., Joel, L.J., Musselman, C., Parker (eds.). Advances in Parasitic Plant Research. Proceedings of the 6th International Symposium on Parasitic Weeds, Cordoba, Spain, 487-493.

Musselman, L.J., 1994. Taxonomy and Spread of Orobanche. Germination Ecology of Striga and Orobanche an Overuiew. Biology and Management of Orobanche, Proceedings of the Third International Workshop on Orobanche and Related Striga Research. Editors, Arnold H. Pieterse Jus A.C., Verkleij Sing, J.ter Burg Royal Tropical İnstitute, The Netherlands, 1994 ,p. 27-35.

Nemli, Y., S.Türkseven, H.Demirkan, A.Uludağ, K.Kaçan, 2009. Patateste Bazı Organik Maddelerin Canavarotu (Orobanche ramosa L. / O.aegyptiaca Pers.) Çıkışına Etkileri. Türkiye III.Bitki Koruma Kongresi, 15-18 Temmuz 2009, VAN. Bildiri Özetleri Kitabı , s:289

Özge, N., Mehmet, H.N., Büyük,H., Dağ, S., 1997. İmazapic Maddesinin Ayçiçeği ve Tütün Ekim Alanlarındaki Canavar Otu (Orobanche spp.)'na Etkinliği Üzerine Araştırmalar. Türkiye II. Herboloji Kongresi, 1-4 Eylül 1997-İzmir ve Ayvalık, 1997.
Parker, C., 1986. Scope of the Agronomic Problems caused by Orobanche species. Biology and control of Orobanche. "Ed.by. S.J. ter Borg" 11-18.

Parker, C., 1994. The Present State of the Orobanche Problem. Germination Ecology of Striga and Orobanche an Overview. Biology and Management of Orobanche, Proceedings of the Third International Workshop on Orobanche and Related Striga Research. Editors, Arnold H. Pieterse Jus A.C., Verkleij Sing, J.ter Burg Royal Tropical Institute, The Netherlands, 1994, p. 17-26.

Quasem, J. R., 1998. Chemical Control of Branched Broomrape (Orabanche ramosa) in glasshouse grown tomato. Crop Protection. 17 (8) : 625-630.

Sauerborn, J., M.C., Saxena, 1986. A Rewiew on Agronomy in Relation to Orobanche Problems in Faba Bean (Vicia faba L.). In SJ Terborg (eds.). Proceedings of a Workshop on Biology and Control of Orobanche. LH/VPO Wageningen, The Netherlands, 160-165.

Schneeweiss, G.M. 2007. Correlated evolution of life history and host range in the non photosynthetic parasitic flowering plants Orobanche and Phelipanche (Orobanchaceae). J. Evol. Biol. 20: $471-478$ 